
sealed area atmosphere is not monitored, and greater than $828 \mathrm{kPa}(120 \mathrm{psig})$ if the sealed area atmosphere is not monitored and certain conditions exist that might lead to higher explosion pressures.

From 2001 to 2007, the NIOSH Office of Mine Safety and Health Research conducted studies to develop alternative ways to determine the adequacy of coal mine seals. The researchers compared full-scale explosion testing within the Lake Lynn Experimental Mine to full-scale hydrostatic testing within a chamber using water to load seals to pressure. Researchers found that gradually applying water pressure to twice the expected explosion pressure was equivalent to the effects created by the rapid increase in pressure loading that results from confined explosions. These hydrostatic tests provided stress-strain measurements, determined the ultimate strength of seals, and demonstrated that hydrostatic testing of mine seals was a timely and cost-effective alternative to full-scale explosion testing. Results of these studies should be used with the testing of mine ventilation seals.

\section{NIOSH Recommendations}

Use hydrostatic testing of mine seals in place of or in conjunction with full-scale explosion testing as a means to validate engineering calculations and models.

Use empirical resistance data from the hydrostatic testing to improve or validate design codes. These new data should be considered when using or evaluating design codes.

Test seals under static load to at least twice the explosion design pressure when performing hydrostatic tests.

Conduct additional studies to further refine and quantify the response of various seal designs under different loading conditions.

Utilize only design codes validated by testing for mine seal design.

Visit www.cdc.gov/niosh for more information on mine safety and health including mine ventilation seals, and download NIOSH Publication 2007-144. Authors of Comparison of Methods: Dynamic versus Hydrostatic Testing of Mine Ventilation Seals_Michael J. Sapko, Samuel P. Harteis, and Eric S. Weiss; Office of Mine Safety and Health Research; $\mathrm{NIOSH}$-received the 2009 Alice Hamilton Award in the Engineering and Physical Sciences category.

\section{SAFER • HEALTHIER ・ PEOPLE ${ }^{\text {TM }}$}

U.S. Department of Health and Human Services

Centers for Disease Control and Prevention

National Institute for Occupational Safety and Health

To receive $\mathrm{NIOSH}$ documents or more information about occupational safety and health topics, please contact $\mathrm{NIOSH}$. Telephone: 1-800-cdc-info (1-800-232-4636) | TTY: 1-888-232-6348 | email: cdcinfo@cdc.gov | www.cdc.gov/niosh For a monthly update on news at $\mathrm{NIOSH}$, subscribe to $\mathrm{NIOSH}$ eNews by visiting www.cdc.gov/niosh/eNews. DHHS (NIOSH) Publication No. 2010-159
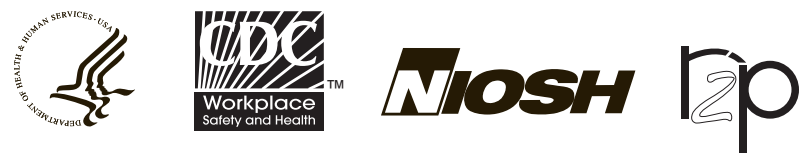